\title{
Notes from the Editor
}

Each year at this time it is my pleasure to acknowledge the contributions that hundreds of reviewers have made to the APSR and, through it, to the profession. The individuals whose names are listed in "APSR External Reviewers 2004-2005" later in this issue served as reviewers-some of several papers-between midAugust 2004 and mid-August 2005. They have my sincere gratitude for their service, sine qua non.

\section{IN THIS ISSUE 1}

Notwithstanding "great man" theories of history, effective political action-a successful revolution, an orderly implementation of a new policy, and so on-generally requires efforts that extend well beyond those of an isolated individual. This issue's cover image of a bridge visually fixes the common thread of interconnectedness that runs through the first four of our otherwise wide-ranging set of November articles. In these articles, cultures collide in the courtroom, advocates argue environmental policy, states vie for a competitive edge, and neighboring cultures learn to coexist-but never alone. Be it in societies, interest groups, or political jurisdictions, interests and preferences have far-reaching effects, reshaping the distribution of political winners and losers, reallocating resources and bragging rights, and redefining friends and foes.

Is it wrong to protect or accommodate racial or ethnic minority groups when doing so can imperil the rights of women within those minorities? Although many have posed the issue as one of multiculturalism versus gender equality, Sarah Song doubts that the matter is that clear-cut. In "Majority Norms, Multiculturalism, and Gender Equality," Song recommends scrutiny of minority groups' cultural claims, consideration of the biases of the majority culture, and monitoring for harmful spillover effects that accommodation might create. Analyzing controversies involving Indians' tribal membership, immigrants' criminal defenses, women's citizenship rights, and Mormons' polygamy, Song shows that American history has not been confined to instances in which the majority culture has condemned minority cultural practices, but also has offered examples of how each side can support, encourage, adopt, or overshadow biases in the practices of the other. More broadly, Song's thought-provoking article highlights how cultures change, for better or for worse, over time and in response to their surroundings.

Whereas cultures often just bump into each other, interest groups are often statutorily required to interact in certain policy arenas. In "To Trust an Adversary: Integrating Rational and Psychological Models of Collaborative Policymaking," William D. Leach and Paul A. Sabatier explore two different perspectives-a

\footnotetext{
$\overline{1 \text { Drafted by editorial assistant Lee Michael. }}$
}

rational choice-based approach and a psychological one-to explain the factors that enabled members of watershed stakeholder partnerships in the American West to trust one another and work together on controversial environmental policies. Whereas the rational choice approach suggests a tit-for-tat model of trustbuilding based on the availability of information and of monitoring institutions capable of applying sanctions, psychological models focus on participants' beliefs, cognitive limitations, and perceptions of the legitimacy of the process. Rather than pitting the two explanatory approaches against one other, Leach and Sabatier allow for the possibility that they may operate jointly. The payoff comes when a welter of interview and survey data indicates that each model conveys insights into how these policy elites were able to build trust and work together. Leach and Sabatier's findings not only provide an example of how knowledge can be built on multiple theoretical bases, but help us understand real-life situations in which unlikely allies find themselves able to cooperate.

Interconnectedness is about more than winning culture wars or policy contests. Considerations of learning and economic advantage stand out in "Using Geographic Information Systems to Study Interstate Competition.” William D. Berry and Brady Baybeck use geographic information systems, a new set of tools for political scientists, to some old questions: Do states learn from each other? Do they compete with each other? Berry and Baybeck reassess two often-studied state-level policy issues, lottery adoption and the generosity of welfare benefits, via this new technique, which treats states as geographic spaces with nodes of varying population densities. Just as different-sized planets and stars exert varying amounts of "pull" on other objects in space, new techniques allow for the possibility that states like California and Montana exert differing levels of influence on their neighbors. These and related GIS technologies should be useful in studying not only interactions among American states, but also subnational politics elsewhere and policy diffusion at the international level.

Donna Bahry, Mikhail Koslapov, Polina Kozyreva, and Rick K. Wilson tear down the proposition that "good fences make good neighbors," in "Ethnicity and Trust: Evidence from Russia." Based on data from surveys in Tartarstan and Sakha-Yakutia, Bahry and her colleagues conclude that the amount of interaction among different ethnic groups and trust in government are the strongest indicators of inter-group trust. This novel finding has important implications for questions of group identity and interpersonal trust in multi-ethnic societies, particularly regarding the link between ingroup trust and out-group trust, which the authors conclude are not inversely related. Their counterintuitive conclusion that generalized trust is not the best predictor of inter-group trust should be of considerable interest to a wide range of scholars who focus on 
issues of interconnectedness, such as collective action, ethnicity, and nationalism.

The balance of this issue ranges far and wide, from levying war and concluding peace through domestic politics and institutional design to a bit of political science history as well. The topical smorgasbord begins with another round of war and peace scholarship.

Albert Einstein believed that "You cannot prevent and prepare for war at the same time." In "Military Coercion in Interstate Crises," Branislav L. Slantchev challenges this notion by showing how military mobilization can deter an opponent in a crisis situation. Rather than relying on classic arguments about audience costs, Slantchev uses an elegant model to demonstrate how military mobilization simultaneously ties the hands of politicians and sinks costs, doubly signaling the mobilizer's resolve. This innovative treatment of tacit bargaining during crises directly challenges the contention of democratic peace theory advocates that democracies are better able to signal their intentions because they face higher audience costs. Slantchev's contention that autocracies are able to signal their intentions as well as democracies when military means are available to them is likely to spark several additional rounds of debate on the causes of war and peace.

When the fighting stops, peace is inaugurated with paperwork: treaties and other international agreements are often considered to be long-lasting guarantees of behavior and obligations between signatories. Visions of parchment, quill pens, and elaborate signing ceremonies in gilded halls or on carrier decks that usher in new eras of cooperation come to mind. However, Barbara Koremenos' research on international agreements on economics, the environment, human rights, and security, as reported in "Contracting around International Uncertainty," reveals that states more often than not make multiple short-term arrangements in the face of an uncertain international environment. Koremenos' analysis should be of interest not only to the international relations scholars, but also to others with interests in institutions and institutional design, including both Americanists and comparativists.

Those Americanists and comparativists will already be interested in identifying constitutional structures that give rise to "good government." John Gerring, Strom C. Thacker, and Carola Moreno take a broad view of this question in "A Centripetal Theory of Democratic Governance: A Theory and Global Inquiry," based on debates about presidentialism versus parliamentarianism, federalism versus unitarism, and single-member districts versus proportional representation. Gerring and associates believe that the latter types of institutions, which form the basis of centripetalism, facilitate higher standards of living and good governance compared to states with vertical and horizontal separations of power. In this sense, that government governs best which governs most-an argument that promises to reignite the debate about whether and in what ways centralized authority and broad inclusiveness are superior means to democratic ends.
Another important question about democratic ends concerns the role of the courts in democratic decision making. While judicial review is often interpreted as an assault on the policy making prerogatives of elected officials, Keith E. Whittington's “'Interpose your Friendly Hand': Political Supports for the Exercise of Judicial Review by the United States Supreme Court" explores how courts serve the political and electoral needs of the dominant national coalition in overcoming barriers to implementing their political agenda. Using episodes of judicial review by the U.S. Supreme Court as case studies, Whittington sets out to determine when elected officials might find it advantageous to pursue policy and electoral objectives through the judiciary. The result is a novel contribution that should be read not only by only public law scholars, but by Americanists and comparativists who too often ignore the policy making role of the courts.

Asked when political science shifted toward its modern-day embrace of "science," most political scientists would probably identify the turning point as the "behavioral revolution" of the mid-twentieth century. However, John G. Gunnell, in "Political Science on the Cusp: Recovering a Discipline's Past," argues that the changes of the 1950s and "60s were more like an academic reformation than a discipline-altering revolution. The turning point, according to Gunnell, took place during the 1920s. The true founding fathers of modern political science were scholars like G. E. G. Caitlin and W. Y. Elliott, whose works initiated a paradigm shift in political science. Gunnell provides evidence that these then-prominent but now largely forgotten figures deserve a more prominent place in our discipline's annals than they have received to date. (Our publication of this article serves the secondary function of providing another occasion to make known that our November 2006 issue will complete the onehundredth volume of the APSR. As previously announced, our centennial issue will be given over to articles on the theme of the evolution of political science.)

In the December 2000 APSR, Beth A. Simmons argued in "International Law and State Behavior: Commitment and Compliance in International Monetary Affairs" that reputational concerns lead states to comply with their treaty obligations. In the "Forum" section of this issue, Jana von Stein contends in "Do Treaties Constrain or Screen? Selection Bias and Treaty Compliance" that selection bias problems mask states' true motivation for obeying treaty obligations. The key factor, von Stein argues, is the set of conditions that led them to sign the treaty in the first place, not their concern about how other states would respond if they were to shirk. In "The Constraining Power of International Treaties: Theory and Methods," Simmons and Daniel J. Hopkins question the robustness of von Stein's findings, recast Simmons' model to mitigate von Stein's methodological concerns, and conclude that Simmons' original results still hold. This exchange ends here so far as the APSR is concerned, but research on the vital question of treaties and state behavior will surely continue. 


\section{INSTRUCTIONS TO CONTRIBUTORS}

\section{General Considerations}

The APSR strives to publish scholarly research of exceptional merit, focusing on important issues and demonstrating the highest standards of excellence in conceptualization, exposition, methodology, and craftsmanship. Because the APSR reaches a diverse audience of scholars and practitioners, authors must demonstrate how their analysis illuminates a significant research problem, or answers an important research question, of general interest in political science. For the same reason, authors must strive for a presentation that will be understandable to as many scholars as possible, consistent with the nature of their material.

The APSR publishes original work. Therefore, authors should not submit articles containing tables, figures, or substantial amounts of text that have already been published or are forthcoming in other places, or that have been included in other manuscripts submitted for review to book publishers or periodicals (including on-line journals). In many such cases, subsequent publication of this material would violate the copyright of the other publisher. The APSR also does not consider papers that are currently under review by other journals or duplicate or overlap with parts of larger manuscripts that have been submitted to other publishers (including publishers of both books and periodicals). Submission of manuscripts substantially similar to those submitted or published elsewhere, or as part of a book or other larger work, is also strongly discouraged. If you have any questions about whether these policies apply in your particular case, you should discuss any such publications related to a submission in a cover letter to the Editor. You should also notify the Editor of any related submissions to other publishers, whether for book or periodical publication, that occur while a manuscript is under review by the APSR and which would fall within the scope of this policy. The Editor may request copies of related publications.

If your manuscript contains quantitative evidence and analysis, you should describe your procedures in sufficient detail to permit reviewers to understand and evaluate what has been done and, in the event that the article is accepted for publication, to permit other scholars to carry out similar analyses on other data sets. For example, for surveys, at the least, sampling procedures, response rates, and question wordings should be given; you should calculate response rates according to one of the standard formulas given by the American Association for Public Opinion Research, Standard Definitions: Final Dispositions of Case Codes and Outcome Rates for Surveys (Ann Arbor, MI: AAPOR, 2000). This document is available on the Internet at $<$ http://www.aapor.org/default.asp? page $=$ survey_methods/standards_and_best_practices/ standard_definitions $>$. For experiments, provide full descriptions of experimental protocols, methods of subject recruitment and selection, subject payments and debriefing procedures, and so on. Articles should be self-contained, so you should not simply refer read- ers to other publications for descriptions of these basic research procedures.

Please indicate variables included in statistical analyses by capitalizing the first letter in the variable name and italicizing the entire variable name the first time each is mentioned in the text. You should also use the same names for variables in text and tables and, wherever possible, should avoid the use of acronyms and computer abbreviations when discussing variables in the text. All variables appearing in tables should have been mentioned in the text and the reason for their inclusion discussed.

As part of the review process, you may be asked to submit additional documentation if procedures are not sufficiently clear; the review process works most efficiently if such information is given in the initial submission. If you advise readers that additional information is available, you should submit printed copies of that information with the manuscript. If the amount of this supplementary information is extensive, please inquire about alternate procedures.

The APSR uses a double-blind review process. You should follow the guidelines for preparing anonymous copies in the Specific Procedures section below.

Manuscripts that are largely or entirely critiques or commentaries on previously published APSR articles will be reviewed using the same general procedures as for other manuscripts, with one exception. In addition to the usual number of reviewers, such manuscripts will also be sent to the scholar(s) whose work is being criticized, in the same anonymous form that they are sent to reviewers. Comments from the original author(s) to the Editor will be invited as a supplement to the advice of reviewers. This notice to the original author(s) is intended (1) to encourage review of the details of analyses or research procedures that might escape the notice of disinterested reviewers; (2) to enable prompt publication of critiques by supplying criticized authors with early notice of their existence and, therefore, more adequate time to reply; and (3) as a courtesy to criticized authors. If you submit such a manuscript, you should therefore send as many additional copies of their manuscripts as will be required for this purpose.

Manuscripts being submitted for publication should be sent to Lee Sigelman, Editor, American Political Science Review, Department of Political Science, The George Washington University, Washington, DC 20052. Correspondence concerning manuscripts under review may be sent to the same address or e-mailed to apsr@gwu.edu.

\section{Manuscript Formatting}

Manuscripts should not be longer than 45 pages including text, all tables and figures, notes, references, and appendices. This page size guideline is based on the U.S. standard $8.5 \times 11$-inch paper; if you are submitting a manuscript printed on longer paper, you must adjust accordingly. The font size must be at least 11 points for all parts of the paper, including notes and references. The entire paper, including notes and references, must be double-spaced, with the sole exception of tables 
for which double-spacing would require a second page otherwise not needed. All pages should be numbered in one sequence, and text should be formatted using a normal single column no wider than 6.5 inches, as is typical for manuscripts (rather than the double-column format of the published version of the APSR), and printed on one side of the page only. Include an abstract of no more than 150 words. The APSR style of embedded citations should be used, and there must be a separate list of references at the end of the manuscript. Do not use notes for simple citations. These specifications are designed to make it easier for reviewers to read and evaluate papers. Papers not adhering to these guidelines are subject to being rejected without review.

For submission and review purposes, you may place footnotes at the bottom of the pages instead of using endnotes, and you may locate tables and figures (on separate pages and only one to a page) approximately where they fall in the text. However, manuscripts accepted for publication must be submitted with endnotes, and with tables and figures on separate pages at the back of the manuscript with standard indications of text placement, e.g., [Table 3 about here]. In deciding how to format your initial submission, please consider the necessity of making these changes if your paper is accepted. If your paper is accepted for publication, you will also be required to submit camera-ready copy of graphs or other types of figures. Instructions will be provided.

For specific formatting style of citations and references, please refer to articles in the most recent issue of the APSR. For unusual style or formatting issues, you should consult the latest edition of The Chicago Manual of Style. For review purposes, citations and references need not be in specific APSR format, although some generally accepted format should be used, and all citation and reference information should be provided.

\section{Specific Procedures}

Please follow these specific procedures for submission:

1. You are invited to submit a list of scholars who would be appropriate reviewers of your manuscript. The Editor will refer to this list in selecting reviewers, though there obviously can be no guarantee that those you suggest will actually be chosen. Do not list anyone who has already commented on your paper or an earlier version of it, or any of your current or recent collaborators, institutional colleagues, mentors, students, or close friends.

2. Submit five copies of manuscripts and a diskette or CD containing a pdf file of the anonymous version of the manuscript. If you cannot save the manuscript as a pdf, just send in the diskette or $\mathrm{CD}$ with the word-processed version. Please ensure that the paper and diskette or CD versions you submit are identical; the diskette or $C D$ version should be of the anonymous copy (see below). Please review all pages of all copies to make sure that all copies contain all tables, figures, appendices, and bibliography mentioned in the manuscript and that all pages are legible. Label the diskette or CD clearly with the (first) author's name and the title of the manuscript (in abridged form if need be), and identify the word processing program and operating system. If you are unable to create a diskette or $\mathrm{CD}$, please note this in your submission, and you will be asked to e-mail the appropriate file.

3. To comply with the APSR's procedure of double-blind peer reviews, only one of the five copies submitted should be fully identified as to authorship and four should be in anonymous format.

4. For anonymous copies, if it is important to the development of the paper that your previous publications be cited, please do this in a way that does not make the authorship of the submitted paper obvious. This is usually most easily accomplished by referring to yourself in the third person and including normal references to the work cited in the list of references. In no circumstances should your prior publications be included in the bibliography in their normal alphabetical location but with your name deleted. Assuming that text references to your previous work are in the third person, you should include full citations as usual in the bibliography. Please discuss the use of other procedures to render manuscripts anonymous with the Editor prior to submission. You should not thank colleagues in notes or elsewhere in the body of the paper or mention institution names, web page addresses, or other potentially identifying information. All acknowledgments must appear on the title page of the identified copy only. Manuscripts that are judged not anonymous will not be reviewed.

5. The first page of the four anonymous copies should contain only the title and an abstract of no more than 150 words. The first page of the identified copy should contain (a) the name, academic rank, institutional affiliation, and contact information (mailing address, telephone, fax, e-mail address) for all authors; (b) in the case of multiple authors, an indication of the author who will receive correspondence; (c) any relevant citations to your previous work that have been omitted from the anonymous copies; and (d) acknowledgments, including the names of anyone who has provided comments on the manuscript. If the identified copy contains any unique references or is worded differently in any way, please mark this copy with "Contains author citations" at the top of the first page.

No copies of submitted manuscripts can be returned. 


\section{ELECTRONIC ACCESS TO THE APSR}

Back issues of the APSR are available in several electronic formats and through several vendors. Except for the last three years (as an annually "moving wall"), back issues of the APSR beginning with Volume 1, Number 1 (November 1906), are available on-line through JSTOR (http://www.jstor.org/). At present, JSTOR's complete journal collection is available only via institutional subscription, e.g., through many college and university libraries. For APSA members who do not have access to an institutional subscription to JSTOR, individual subscriptions to its $A P S R$ content are available. Please contact Member Services at APSA for further information, including annual subscription fees.

Individual members of the American Political Science Association can access recent issues of the APSR and $P S$ through the APSA website (www.apsanet.org) with their username and password. Individual nonmember access to the online edition will also be available, but only through institutions that hold either a print-plus-electronic subscription or an electronic-only subscription, provided the institution has registered and activated its online subscription.

Full text access to current issues of both the APSR and $P S$ is also available on-line by library subscription from a number of database vendors. Currently, these include University Microfilms Inc. (UMI) (via its CDROMs General Periodicals Online and Social Science Index and the on-line database ProQuest Direct), Online Computer Library Center (OCLC) (through its on-line database First Search as well as on CD-ROMs and magnetic tape), and the Information Access Company (IAC) (through its products Expanded Academic Index, InfoTrac, and several on-line services [see below]). Others may be added from time to time.

The APSR is also available on databases through six online services: Datastar (Datastar), Business Library (Dow Jones), Cognito (IAC), Encarta Online Library (IAC), IAC Business (Dialog), and Newsearch (Dialog).

The editorial office of the APSR is not involved in the subscription process to either JSTOR for back issues or the other vendors for current issues. Please contact APSA, your reference librarian, or the database vendor for further information about availability.

\section{BOOK REVIEWS}

The APSR no longer contains book reviews. As of 2003, book reviews have moved to Perspectives on Politics. All books for review should be sent to the Perspectives on Politics Book Review Editor, Jeffrey C. Isaac. The address is Professor Jeffrey C. Isaac, Review Editor, Perspectives on Politics, Department of Political Science, Woodburn Hall, 1100 E. 7th St., Indiana University, Bloomington, IN 47405-7110. E-mail: isaac@indiana.edu.

If you are the author of a book you wish to be considered for review, please ask your publisher to send a copy to the Perspectives on Politics Book Review Editor per the mailing instructions above. If you are interested in reviewing books for Perspectives on Politics, please send your vita to the Book Review Editor; you should not ask to review a specific book.

\section{OTHER CORRESPONDENCE}

The American Political Science Association's address, telephone, and fax are 1527 New Hampshire Avenue, N.W., Washington, D.C. 20036, (202) 483-2512 (voice), and (202) 483-2657 (fax). E-mail: apsa@apsanet.org. Please direct correspondence as follows.

Information, including news and notes, for PS:

Dr. Robert J-P. Hauck, Editor, PS

E-mail:rhauck@apsanet.org

Circulation and subscription correspondence (domestic claims for nonreceipt of issues must be made within four months of the month of publication; overseas claims, within eight months):

Sean Twombly,

Director of Member Services

E-mail: membership@apsanet.org

Reprint permissions:

E-mail: Rights@cambridge.org

Advertising information and rates:

Advertising Coordinator,

Cambridge University Press

E-mail: advertising@apsanet.org

\section{EXPEDITING REQUESTS FOR COPYING APSR AND PS ARTICLES FOR CLASS USE AND OTHER PURPOSES}

\section{Class Use}

The Comprehensive Publisher Photocopy Agreement between APSA and the Copyright Clearance Center (CCC) permits bookstores and copy centers to receive expedited clearance to copy articles from the $A P S R$ and $P S$ in compliance with the Association's policies and applicable fees. The general fee for articles is 75 cents per copy. However, current Association policy levies no fee for the first 10 copies of a printed artide, whether in course packs or on reserve. Smaller classes that rely heavily on articles (i.e., upper-level undergraduate and graduate classes) can take advantage of this provision, and faculty ordering 10 or fewer course packs should bring it to the attention of course pack providers. APSA policy also permits free use of the electronic library reserve, with no limit on the number 
of students who can access the electronic reserve. Both large and small classes that rely on these articles can take advantage of this provision. The CCC's address, telephone, and fax are 222 Rosewood Drive, Danvers, MA 01923, (978) 750-8400 (voice), and (978) 750-4474 (fax). This agreement pertains only to the reproduction and distribution of APSA materials as hard copies (e.g., photocopies, microfilm, and microfiche).

The Association of American Publishers (AAP) has created a standardized form for college faculty to submit to a copy center or bookstore to request copyrighted material for course packs. The form is available through the CCC, which will handle copyright permissions.

APSA also has a separate agreement pertaining to CCC's Academic E-Reserve Service. This agreement allows electronic access for students and instructors of a designated class at a designated institution for a specified article or set of articles in electronic format. Access is by password for the duration of a class.

Please contact your librarian, the CCC, or the APSA Reprints Department for further information.

\section{APSR Authors}

If you are the author of an APSR article, you may use your article in course packs or other printed materials without payment of royalty fees and you may post it at personal or institutional web sites as long as the APSA copyright notice is included.

\section{Other Uses of APSA-Copyrighted Materials}

For any further copyright issues, please contact the APSA Reprints Department.

\section{INDEXING}

Articles appearing in the APSR before June 1953 were indexed in The Reader's Guide to Periodical Literature. Current issues are indexed in ABC Pol Sci; America, History and Life 1954-; Book Review Index; Current Contents: Social and Behavioral Sciences; EconLit; Energy Information Abstracts; Environmental Abstracts; Historical Abstracts; Index of Economic Articles; Information Service Bulletin; International Index; International Political Science Abstracts; the Journal of Economic Literature; Periodical Abstracts; Public Affairs; Public Affairs Information Service International Recently Published Articles; Reference Sources; Social Sciences and Humanities Index; Social Sciences Index; Social Work Research and Abstracts; and Writings on American History. Some of these sources may be available in electronic form through local public or educational libraries. Microfilm of the APSR, beginning with Volume 1 , and the index of the APSR through 1969 are available through University Microfilms Inc., 300 North Zeeb Road, Ann Arbor, MI 48106 (www.umi.com). The Cumulative Index to the American Political Science Review, Volumes 63 to 89: 1969-95, is available through the APSA. 